\title{
Microwave Promoted Palladium-Catalyzed Oxyarylation of Dihydronaphthalene and Chromenes by o-lodophenols and its Acetates
}

\section{Camilla D. Buarque ${ }^{\mathrm{a}, \mathrm{c}}$,Raquel A. C. Leão, ${ }^{\mathrm{a}}$ Vagner D. Pinho, ${ }^{\mathrm{a}}$ Artur S. Coelho, ${ }^{\mathrm{a}}$ Paula F. Moraes, ${ }^{a}$ Diego A. Alonso, ${ }^{b}$ Carmen Nájera, ${ }^{* b}$ and Paulo R. R. Costa ${ }^{\star a}$}

a Laboratório de Química Bioorgânica, NPPN, CCS, Ilha da Cidade Universitária, Universidade Federal do Rio de janeiro, Rio de Janeiro, RJ 21941-590, Brazil. ${ }^{b}$ Departamento de Química Orgánica, Facultad de

Ciencias and Instituto de Síntesis Orgánica (ISO), Alicante University, Apdo. 99, E-03080, Alicante, Spain.

${ }^{c}$ Departamento de Química, Pontifícia Universidade Católica do Rio de Janeiro, Rua Marquês de S. Vicente, 225, Gávea - Rio de Janeiro, RJ-Brasil-22453-900

*e-mail: prrcosta2011@gmail.com

Keywords: oxyarylation, chromenes, o-iodophenols

\section{INTRODUCTION}

Oxyarylation of olefins has been used by our group to prepare naturally occurring pterocarpans and derivatives. ${ }^{1}$ Recently we reported the oxyarylation of dihydronaphthalene and chromenes by 0 iodophenols under conditions favouring the cationic mechanism, reactions which were analyzed by ESI$M S{ }^{2}$ In this paper we describe the scope of these oxyarylations using electron-rich 2a-c and one electron-poor olefins $\mathbf{3}$ with ortho-iodophenols and its acetates 1a-h under microwave irradiation. ${ }^{3}$

\section{RESULTS AND DISCUSSION}

In Figure 1 are shown the ortho-iodophenols (1), electron rich olefins (2) and one electron poor olefin (3) used in this work. The reaction of $\mathbf{1}$ with $\mathbf{2}$ lead to pterocarpan derivatives 4 while reaction of $\mathbf{1}$ with $\mathbf{3}$ furnish pterocarpanquinones 5 .

In one set of reactions, $\mathrm{Pd}(\mathrm{OAc})_{2}(10 \mathrm{~mol} \%)$ was used as precatalyst in the presence of $\mathrm{Ag}_{2} \mathrm{CO}_{3}$ as base, in acetone as solvent (Conditions $A$ ) while in the other set of experiments an oxime-based palladacycle (2 mol\% $\mathrm{Pd}$ ) was used as precatalyst, in the presence of $\mathrm{Cy}_{2} \mathrm{NH}$ as base in $\mathrm{DMA} / \mathrm{H}_{2} \mathrm{O}$ as solvent.In both cases the reaction mixtures were submeitted to microwave irradiation, for $40 \mathrm{~min}$.

The reactions studied were accelerated when accomplished under microwave irradiation (40 min. $\mathrm{X} 24 \mathrm{~h}$ for thermal process). Conditions $\mathrm{A}$ are the best choice for these reactions, for both electron-rich and electron-poor olefins, although in some cases yields obtained using the oxime-based palladacycle 5 as pre-catalyst were reasonable. The better yields of oxyarylation were observed for the reactions of electron-rich olefins with ortho-iodophenols substituted by electron-withdrawing groups. In contrast, for the electron-poor quinone, better yields were obtained using the electron-rich o-iodophenol.

Figure 1. Olefins, ortho-iodophenols, palladium precatalyst source and conditions for the reactions between $\mathbf{1}+\mathbf{2}$ or $\mathbf{1}+\mathbf{3}$ leading to $\mathbf{4}$ and $\mathbf{5}$, respectively.
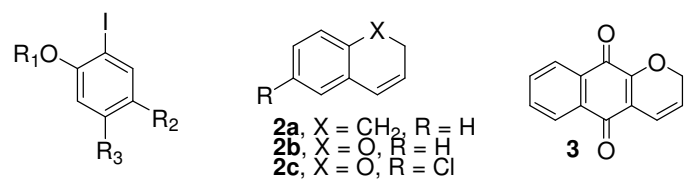

1a: $R^{1}=R^{2}=R^{3}=H$

1b: $R_{1}=A c, R^{2}=R^{3}=H$

1c: $R^{1}=R^{3}=\mathrm{H}, \mathrm{R}^{2}=\mathrm{CO}_{2} \mathrm{Me}$

1d, $R^{1}=A c, R^{3}=H, R^{2}=C_{2} M e$

1e, $R^{1}=R^{3}=\mathrm{H}, \mathrm{R}^{2}=\mathrm{NO}_{2}$

1, $\mathrm{R}^{1}=\mathrm{Ac}, \mathrm{R}^{3}=\mathrm{H}, \mathrm{R}^{2}=\mathrm{NO}_{2}$

1g, $R^{1}=R^{2}=H ; R_{3}=O M e$

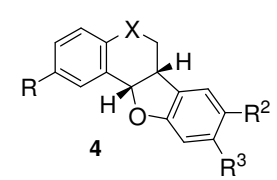

1h, $R^{1}=A c, R^{2}=H, R^{3}=O M e$
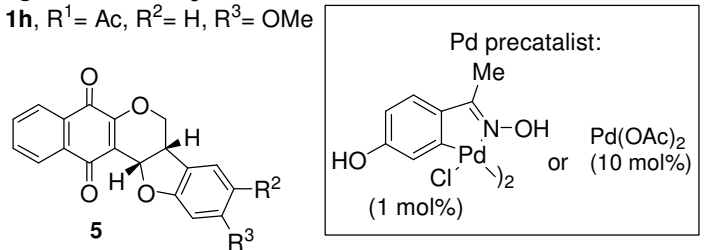

A: $\mathrm{Pd}(\mathrm{OAc})_{2}(10 \mathrm{~mol} \%), \mathrm{Ag}_{2} \mathrm{CO}_{3}$ (1.5 equiv.), acetone, $60 \stackrel{\circ}{\mathrm{C}}, 40 \mathrm{~min}$., microwave irradiation

B: Palladacycle (2 mol\% Pd), $\mathrm{Cy}_{2} \mathrm{NH}$ (2 equiv.), DMA $/ \mathrm{H}_{2} \mathrm{O}, 120 \stackrel{\circ}{\mathrm{C}}, 40 \mathrm{~min}$., microwave irradiation

\section{ACKNOWLEDGEMENTS}

CAPES, CNPq, FAPERJ

\section{REFERENCES}

${ }^{1}$ A. J. M. da Silva, C. D. Buarque, F. V. Brito, L. Aurelian, L. F. Macedo, L. H. Malkas, R. J. Hickey, D. V. S. Lopes, F. Noël, Y. L. B. Murakami, N. M. V. Silva, P. A. Melo, R. R. B. Caruso, N. G. Castro, P. R. R. Costa, Bioorg. Med. Chem. 2002, 10, 2731.

${ }^{2}$ C. D. Buarque, V. D. Pinho, B. G. Vaz, M. N. Eberlin, A. J. M. da Silva, P. R. R. Costa, J. Organomet. Chem. 2010, 695, 2062.

${ }^{3}$ Leão, R.A.C.; Pinho, V.D.; Coelho, A.S.; Buarque, C.D.; Moraes, P.F.; Alonso, D.; Nájera, C.; Costa, P.R.R Eur. J. Org. Chem. In press. 